\title{
Effect of ion flux on helium retention in helium-irradiated tungsten
}

\author{
A. Rivera ，G. Valles , M.J. Caturla , I. Martin-Bragado
}

\begin{abstract}
A B S T R A C T
Helium retention in irradiated tungsten leads to swelling, pore formation, sample exfoliation and embrittlement with deleterious consequences in many applications. In particular, the use of tungsten in future nuclear fusion plants is proposed due to its good refractory properties. However, serious concerns about tungsten survivability stems from the fact that it must withstand severe irradiation conditions. In magnetic fusion as well as in inertial fusion (particularly with direct drive targets), tungsten components will be exposed to low and high energy ion irradiation (helium), respectively. A common feature is that the most detrimental situations will take place in pulsed mode, i.e., high flux irradiation. There is increasing evidence of a correlation between a high helium flux and an enhancement of detrimental effects on tungsten. Nevertheless, the nature of these effects is not well understood due to the subtleties imposed by the exact temperature profile evolution, ion energy, pulse duration, existence of impurities and simultaneous irradiation with other species. Object Kinetic Monte Carlo is the technique of choice to simulate the evolution of radiation-induced damage inside solids in large temporal and space scales. We have used the recently developed code MMonCa (Modular Monte Carlo simulator), presented at COSIRES 2012 for the first time, to study He retention (and in general defect evolution) in tungsten samples irradiated with high intensity helium pulses. The code simulates the interactions among a large variety of defects and during the irradiation stage and the subsequent annealing steps. The results show that the pulsed mode leads to significantly higher He retention at temperatures higher than $700 \mathrm{~K}$. In this paper we discuss the process of He retention in terms of trap evolution. In addition, we discuss the implications of these findings for inertial fusion.
\end{abstract}

\section{Introduction}

Tungsten is usually proposed as an appropriate material for nuclear fusion reactors. This is due to a number of features that it presents: low sputtering yield, low-activation, high melting point, high thermal conductivity and low thermal expansion [1-3]. In the case of inertial confinement fusion by laser (laser fusion) with direct drive targets (as it is the case of the European project HiPER) $\mathrm{W}$ is proposed as an armor material [4,5] with the function of protecting the underlying structural materials against the intense ion fluxes stemming from the target explosions. Furthermore, $\mathrm{W}$ is considered the material of choice for the first wall and divertor of future magnetic fusion power plants [6,7]. In this case, W will have to protect the structure against the severe irradiation conditions and in addition, some parts of the $\mathrm{W}$-based divertor will have to present good mechanical properties to serve as structural component.
In both cases, laser (with direct drive target) and magnetic fusion, the most detrimental situations that $\mathrm{W}$ components must face are originated by intense ion pulses [4]. These pulses produce very high thermal loads $[8,9]$ that may result in fatal thermomechanical response of the $\mathrm{W}$ components. Appropriate chamber geometry, radiation mitigation strategies, materials engineering and a reduced target yield may lead to an acceptable thermomechanical response $[9,10]$. However, even considering that the thermo-mechanical response can be under control, there exists a serious issue concerning $\mathrm{He}$ irradiation. Numerous studies $[11,12]$ carried out under different conditions in continuous mode He irradiation show that exceeding certain threshold value of fluence, around $10^{17}-10^{18} \mathrm{He} / \mathrm{cm}^{2}$, has fatal consequences for the W components. SEM images reveal that swelling and pore formation take place that eventually lead to $\mathrm{W}$ exfoliation with mass loss. A recent paper by Renk and co-workers [13] clearly shows that the situation is worse when $W$ is subject to intense He pulses rather than to continuous irradiation. In this situation the fluence threshold for mass loss appears to be two orders of magnitude lower. This has serious implications for fusion reactor $\mathrm{W}$-based components 
Table 1

Binding energy of different reactions according to the parametrization made by Becquart and co-workers [15].

\begin{tabular}{llll}
\hline Reaction & $\begin{array}{l}\mathrm{He} \\
\text { binding } \\
\text { energy } \\
(\mathrm{eV})\end{array}$ & Reaction & $\begin{array}{l}\mathrm{He} \\
\text { binding } \\
\text { energy } \\
(\mathrm{eV})\end{array}$ \\
\hline $\mathrm{He}+\mathrm{v} \rightarrow \mathrm{He} \cdot \mathrm{v}$ & 4.57 & $\mathrm{v}+\mathrm{He} \rightarrow \mathrm{He} \cdot \mathrm{v}$ & 4.57 \\
$\mathrm{He}+\mathrm{He} \cdot \mathrm{v} \rightarrow 2 \mathrm{He} \cdot \mathrm{v}$ & 3.11 & $\mathrm{v}+\mathrm{He} \cdot \mathrm{v} \rightarrow \mathrm{He} \cdot 2 \mathrm{v}$ & 0.07 \\
$\mathrm{He}+2 \mathrm{He} \cdot \mathrm{v} \rightarrow 3 \mathrm{He} \cdot \mathrm{v}$ & 3.28 & $\mathrm{v}+\mathrm{He} \cdot 2 \mathrm{v} \rightarrow \mathrm{He} \cdot 3 \mathrm{v}$ & 0.70 \\
$\mathrm{He}+3 \mathrm{He} \cdot \mathrm{v} \rightarrow 4 \mathrm{He} \cdot \mathrm{v}$ & 2.61 & $\mathrm{v}+\mathrm{He} \cdot 3 \mathrm{v} \rightarrow \mathrm{He} \cdot 4 \mathrm{v}$ & 1.01 \\
$\mathrm{He}+4 \mathrm{He} \cdot \mathrm{v} \rightarrow 5 \mathrm{He} \cdot \mathrm{v}$ & 1.44 & $\mathrm{v}+2 \mathrm{He} \rightarrow 2 \mathrm{He} \cdot \mathrm{v}$ & 6.65 \\
$\mathrm{He}+5 \mathrm{He} \cdot \mathrm{v} \rightarrow 6 \mathrm{He} \cdot \mathrm{v}$ & 2.08 & $\mathrm{v}+2 \mathrm{He} \cdot \mathrm{v} \rightarrow 2 \mathrm{He} \cdot 2 \mathrm{v}$ & 1.82 \\
$\mathrm{He}+2 \mathrm{v} \rightarrow \mathrm{He} \cdot 2 \mathrm{v}$ & 4.69 & $\mathrm{v}+2 \mathrm{He} \cdot 2 \mathrm{v} \rightarrow 2 \mathrm{He} \cdot 3 \mathrm{v}$ & 0.68 \\
$\mathrm{He}+\mathrm{He} \cdot 2 \mathrm{v} \rightarrow 2 \mathrm{He} \cdot 2 \mathrm{v}$ & 4.85 & $\mathrm{v}+2 \mathrm{He} \cdot 3 \mathrm{v} \rightarrow 2 \mathrm{He} \cdot 4 \mathrm{v}$ & 1.29 \\
$\mathrm{He}+2 \mathrm{He} \cdot 2 \mathrm{v} \rightarrow 3 \mathrm{He} \cdot 2 \mathrm{v}$ & 3.97 & $\mathrm{v}+3 \mathrm{He} \rightarrow 3 \mathrm{He} \cdot \mathrm{v}$ & 8.57 \\
$\mathrm{He}+3 \mathrm{v} \rightarrow \mathrm{He} \cdot 3 \mathrm{v}$ & 5.35 & $\mathrm{v}+3 \mathrm{He} \cdot \mathrm{v} \rightarrow 3 \mathrm{He} \cdot 2 \mathrm{v}$ & 2.65 \\
$\mathrm{He}+\mathrm{He} \cdot 3 \mathrm{v} \rightarrow 2 \mathrm{He} \cdot 3 \mathrm{v}$ & 4.83 & $\mathrm{v}+3 \mathrm{He} \cdot 2 \mathrm{v} \rightarrow 3 \mathrm{He} \cdot 3 \mathrm{v}$ & 1.83 \\
$\mathrm{He}+2 \mathrm{He} \cdot 3 \mathrm{v} \rightarrow 3 \mathrm{He} \cdot 3 \mathrm{v}$ & 5.08 & $\mathrm{v}+3 \mathrm{He} \cdot 3 \mathrm{v} \rightarrow 3 \mathrm{He} \cdot 4 \mathrm{v}$ & 1.49 \\
$\mathrm{He}+4 \mathrm{v} \rightarrow \mathrm{He} \cdot 4 \mathrm{v}$ & 5.74 & $\mathrm{v}+4 \mathrm{He} \rightarrow 4 \mathrm{He} \cdot \mathrm{v}$ & 10.22 \\
$\mathrm{He}+\mathrm{He} \cdot 4 \mathrm{v} \rightarrow 2 \mathrm{He} \cdot 4 \mathrm{v}$ & 5.11 & & \\
$\mathrm{He}+2 \mathrm{He} \cdot 4 \mathrm{v} \rightarrow 3 \mathrm{He} \cdot 4 \mathrm{v}$ & 5.29 & & \\
$\mathrm{He}+3 \mathrm{He} \cdot 4 \mathrm{v} \rightarrow 4 \mathrm{He} \cdot 4 \mathrm{v}$ & 5.17 & &
\end{tabular}

because, as discussed above, the most relevant irradiation situations are driven by intense ion pulses.

The origin of these adverse effects upon He irradiation is unclear, however, it is logical to consider excessive He retention as a possible cause [13]. A detailed study of He retention is not trivial due to the subtleties imposed by the exact temperature profile, ion energy, pulse duration and the presence of impurities, which lead to complicated evolution of defect clusters. The technique of choice to follow in detail the evolution of radiation-induced damage is Object Kinetic Monte Carlo (OKMC). It allows one to follow relatively large systems (of the $\mu \mathrm{m}^{3}$ order) in timescales as long as hours-days. We have used the new code MMonCa [14], presented at COSIRES 2012, for the comparison of $3 \mathrm{keV}$ He-irradiated W in continuous and pulsed modes at different temperatures. The results clearly indicate that in fact He retention is significantly higher in the case of pulsed irradiation, provided the temperature is high enough $(>700 \mathrm{~K})$ to enable vacancy motion.

\section{Method}

We have used the OKMC code MMonCa to simulate $3 \mathrm{keV} \mathrm{He}$ irradiation of $\mathrm{W}$ at different temperatures and flux conditions. We have used a previous complex parametrization of the $\mathrm{W}$ system presented by Becquart and co-workers $[15,16]$. We employ a $126 \times 126 \times 317$ (depth) $\mathrm{nm}^{3} \mathrm{~W}$ box. He ions hit the top surface along the $X$ axis. We use periodic boundary conditions on the $Y$ and $Z$ dimensions. The generated vacancies ( $v$ ) and interstitials (i) may migrate, annihilate or cluster. Clusters of vacancies and interstitials are also mobile and may annihilate at the surfaces. The implanted He may form mobile interstitial He clusters that may desorb from the surface. In addition, interstitial He(-clusters) may form mixed $\mathrm{He} \cdot \mathrm{v}$ or $\mathrm{He} \cdot \mathrm{i}$ clusters that are immobile. Table 1 shows some significant mixed $\mathrm{He} \cdot \mathrm{v}$ clusters and dissociation routes through $\mathrm{v}$ or $\mathrm{He}$ emission.

The aim of this work is to compare pulsed irradiation with continuous irradiation. For the first case we introduce certain amount of $\mathrm{He}\left(2 \times 10^{12}\right.$ or $\left.2 \times 10^{13} \mathrm{~cm}^{-2}\right)$ along with the generated Frenkel pairs and let them evolve for $1 \mathrm{~s}$ at certain temperature until the next He pulse arrives. For the second case, we introduce He ions (and the generated Frenkel pairs) at a constant rate $\left(2 \times 10^{12}\right.$ or $\left.2 \times 10^{13} \mathrm{~cm}^{-2} \mathrm{~s}^{-1}\right)$. Thus, in this case there is a continuous introduction of He ions in the box. Defect evolution is enabled during the irradiation.

\section{Results and discussion}

In order to compare continuous and pulsed He irradiation of W, we simulated with MMonCa the evolution of the defects generated by $3 \mathrm{keV}$ He irradiation under different conditions. Fig. 1(a) and (b) show continuous and pulsed irradiation results, respectively, obtained at different temperatures. Note that in any case the number of implanted He ions averaged over time is the same, i.e., in any case, the $\mathrm{W}$ box receives $2 \times 10^{12} \mathrm{He} \mathrm{cm}^{-2}$. In the pulsed case (Fig. 1(b)) all the ions arrive together at certain time and no more ions arrive until $1 \mathrm{~s}$ later, whereas in the continuous case (Fig. 1(a)) the ions $\left(2 \times 10^{12} \mathrm{He} \mathrm{cm}^{-2}\right)$ arrive distributed uniformly over every second. From the figures, it turns out that there is a clear dependence on temperature: the higher the temperature the lower the He retention, regardless the irradiation mode. At $700 \mathrm{~K}$ the $\mathrm{He}$ retention as a function of irradiation time is very similar in both cases. However, at higher temperatures the He retention is significantly larger in the case of pulsed irradiation. It is very remarkable that at $1600 \mathrm{~K}$, no He is retained in the case of continuous irradiation whereas He retention amounts to $40 \%$ in the case of pulsed irradiation. The difference on He retention between both irradiation modes is less pronounced at lower temperatures but still quite significant. $150 \mathrm{~s}$ after starting the irradiation we observe that at $1000 \mathrm{~K}, \sim 70 \%$ of the total implanted He remains in the sample irradiated in continuous mode and $\sim 80 \%$ in pulsed mode and at $1300 \mathrm{~K}$ the He retention reaches $\sim 30 \%$ in continuous mode and $\sim 70 \%$ in pulsed mode. If we concentrate on the latter temperature $(1300 \mathrm{~K})$ and compare both pulsed and continuous irradiation modes at averaged rates of $2 \times 10^{12}$ and $2 \times 10^{13} \mathrm{He}^{-2}$ every second (Fig. 1(c)), we clearly observe that the He retention is much more pronounced in pulsed mode. In particular, pulsed mode irradiation at the highest flux $\left(2 \times 10^{13} \mathrm{He} \mathrm{cm}^{-2} /\right.$ pulse) leads to almost $100 \%$ retention $150 \mathrm{~s}$ after starting the irradiation.
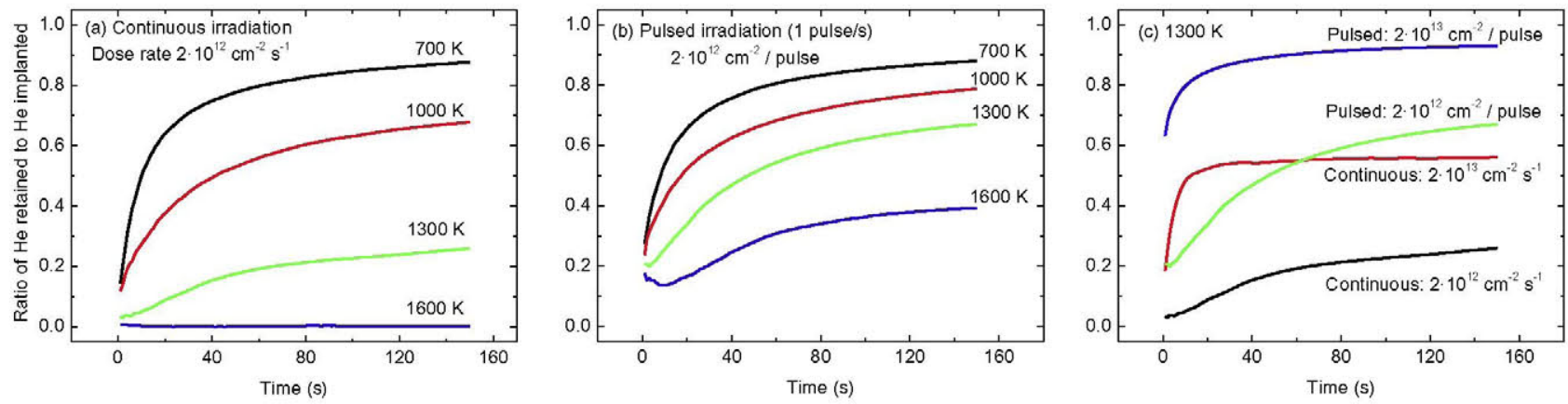

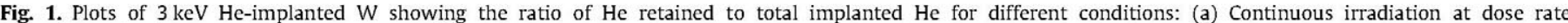

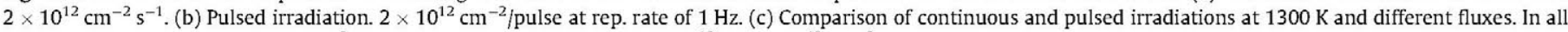
cases, the number of He ions per $\mathrm{cm}^{2}$ averaged over $1 \mathrm{~s}$ is the same $\left(2 \times 10^{12}\right.$ or $\left.2 \times 10^{13} \mathrm{~cm}^{-2}\right)$. 

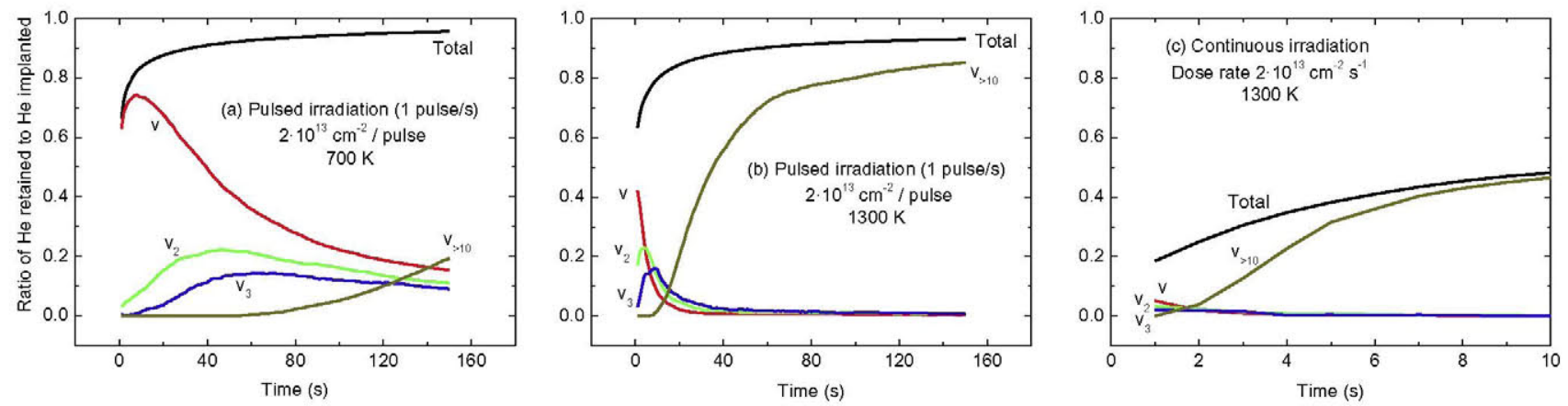

Fig. 2. Plots of $3 \mathrm{keV} \mathrm{He}$-implanted W showing the total He retained fraction and the trapping sites for different conditions: (a) Pulsed irradiation at $700 \mathrm{~K} .2 \times 10^{13} \mathrm{~cm}^{-2}$ / pulse at rep. rate of $1 \mathrm{~Hz}$. (b) Pulsed irradiation at $1300 \mathrm{~K} .2 \times 10^{13} \mathrm{~cm}^{-2} /$ pulse at rep. rate of $1 \mathrm{~Hz}$. (c) Continuous irradiation at dose rate $2 \times 10^{13} \mathrm{~cm}^{-2} \mathrm{~s}^{-1}$. (Note that in this case the horizontal scale is much smaller).

The method provides all the details on the microscopic defect structure. Therefore, we can study where He remains trapped in the different scenarios. At cryogenic temperatures the interstitials play an important role in He retention [16], however, at the irradiation temperatures of this work, the high mobility of interstitials and low $\mathrm{He} \cdot \mathrm{i}$ dissociation energy lead to an almost complete He retention at $\mathrm{He}_{n} \mathrm{v}_{m}$ clusters. Fig. 2(a) corresponds to $700 \mathrm{~K}$ pulsed irradiation. It shows the trapping sites (v-clusters) at which He is retained. In the case of continuous irradiation at this temperature (not shown) the results are very similar. Initially, He is trapped at single vacancies (forming $\mathrm{He} \cdot \mathrm{v}$ defects). With increasing number of pulses, the vacancy clusters grow and He is trapped at $\mathrm{He} \cdot \mathrm{v}_{2}$, He $\cdot \mathrm{v}_{3} \ldots$ defects. Not only has the defect size grown up but also the trapping site concentration. This leads to a continuous increase of He retention up to almost $100 \%$. Mobile He easily finds trapping sites from which it cannot dissociate at this temperature (dissociation energies higher than $1.4 \mathrm{eV}$, see Table 1). The analogous situation at $1300 \mathrm{~K}$ is depicted in Fig. 2(b). At this temperature, He may escape from some traps, remarkably from $\mathrm{He}_{4-5} \cdot \mathrm{V}$ complexes (Table 1). However, vacancy mobility is very high, swiftly resulting in large v-clusters from which He cannot escape The number of implanted He ions per pulse is very high. This generates a very high concentration of traps from the beginning and consequently, an almost $100 \%$ He retention in short times. For comparison, Fig. 2(c) shows irradiation in continuous mode. In this case, at any given moment, the defect concentration in the sample is much lower than in pulsed mode. This results in a significantly lower He retention. In addition, the low defect concentration inhibits v-clustering and the remaining, mainly single vacancies, can easily reach the surface and annihilate. Vacancy aggregation on He-containing vacancies takes place, making large clusters $\left(V_{>10}\right)$ the main trapping site from the first few seconds after starting the irradiation.

\section{Conclusions and implications}

We have shown that $3 \mathrm{keV} \mathrm{He}$ irradiation of $\mathrm{W}$ at $700 \mathrm{~K}$ (or lower) leads to similar retention fractions regardless the irradiation mode (pulsed or continuous). However, at higher temperatures the He retained fractions are significantly higher in pulsed mode due to the larger defect concentrations attained. In continuous mode, however, the defect concentration is so low that vacancy annihilation at the surface effectively competes with vacancy clustering, thus, reducing the trapping site concentration with respect to the pulsed case. The higher He retention in pulsed mode is relevant to the development of fusion materials and may be the origin of the low fluence threshold observed in pulsed irradiation experiments [13]. Further work to reproduce in detail these experiments is underway.

\section{Acknowledgement}

Work supported by Spanish MINECO (project AIC-A-20110718) and by the ECTS Technofusion.

\section{References}

[1] C.H. Wu, C. Alessandrini, R. Moormann, M. Rubel, B.M.U. Scherzer, J. Nucl. Mater. 220-222 (1995) 860.

[2] G. Federici, R.A. Anderl, P. Andrew, J.N. Brooks, R.A. Causey, J.P. Coad, et al., J. Nucl. Mater. 266-269 (1999) 14.

[3] M. Kaufmann, R. Neu, Fusion Eng. Des. 82 (2007) 521-527S

[4] J. Alvarez, R. Gonzalez-Arrabal, A. Rivera, E. Del Rio, D. Garoz, E.R. Hodgson, et al., Fusion Eng. Des. 86 (2011) 1762.

[5] J. Alvarez, A. Rivera, R. Gonzalez-Arrabal, D. Garoz, E. del Rio, J.M. Perlado, Fusion Sci. Technol. 60 (2011) 565.

[6] T. Hirai, H. Maier, M. Rubel, Ph. Mertens, R. Neu, E. Gauthier, et al., Fusion Eng. Des. 82 (2007) 1839.

[7] V. Barabash, ITER International Team, A. Peacock, S. Fabritsiev, G. Kalinin, S. Zinkle, et al., J. Nucl. Mater. 367-370 (2007) 21.

[8] J. Alvarez, D. Garoz, R. Gonzalez-Arrabal, A. Rivera, M. Perlado, Nucl. Fusion 51 (2011) 053019.

[9] A.R. Raffray, L. El-Guebaly, G. Federici, D. Haynes, F. Najmabadi, D. Petti, Fusion Sci. Technol. 46 (2004) 417

[10] T.J. Renk, P.P. Provencio, T.J. Tanaka, C.L. Olson, R.R. Peterson, J.E. Stolp, et al., J. Nucl. Mater. 347 (2005) 266

[11] S.J. Zenobia, G.L. Kulcinski, Phys. Scr. T138 (2009) 014049.

[12] S. Sharafat, A. Takahashi, Q. Hu, N.M. Ghoniem, J. Nucl. Mater. 386-388 (2009) 900.

[13] T.J. Renk, P.P. Provencio, T.J. Tanaka, J.P. Blanchard, C.J. Martin, T.R. Knowles, Fusion Sci. Technol. 61 (2012) 57.

[14] I. Martin-Bragado, A. Rivera, G. Valles, M. J. Caturla, Comput. Phys. Commun., submitted for publication.

[15] C.S. Becquart, C. Domain, J. Nucl. Mater. 385 (2009) 223.

[16] C.S. Becquart, C. Domain, U. Sarkar, A. DeBacker, M. Hou, J. Nucl. Mater. 403 (2010) 75 . 